\title{
Soft Skills of Dental Students' Competence: What is Important for Patients and How do Students Fare?
}

\author{
${ }^{1}$ AM Mohamed, ${ }^{2} \mathrm{D}$ Abdullah, ${ }^{3} \mathrm{TN}$ Mohd Dom
}

\begin{abstract}
Aim: This study aims to evaluate the impact of soft skills' formal assessment on the students' interpersonal competency as evaluated by their own patients.
\end{abstract}

Materials and methods: A validated eight-item questionnaire with a 5-point Likert rating scale addressing relevant soft skills and rated by patients was used for two different cohorts of final year dental undergraduate students at the Universiti Kebangsaan Malaysia, Kuala Lumpur, Malaysia. The first cohort (class of 2009) did not receive a formal daily assessment during their clinical work, while the second batch (class of 2011) did. The daily assessment was used as a formative evaluation and included aspects of professionalism, patient empathy and education, organization of work area, and time management.

Results: For all the eight items in the questionnaire, more than $97 \%$ (total $=340$ ) of the patients responded positively for both batches (2009 and 2011) of dental students. As for the scores related to specific items, there was improvement in the proportions of patients who were satisfied with all the items for the batch of students who had the formal assessment for their clinical work. These improvements, however, did not demonstrate any statistical significance $(p>0.05)$.

Conclusion: Patients were equally satisfied with the soft skills among two groups of final year dental students during clinical encounters. The formal assessment of soft skills did not have any impact on the measured outcomes.

Clinical significance: Soft skills are a learning experience for every dental student, which is useful in personal and professional life. An increase in health service and competitive dental practices emphasizes the need for soft skills to understand the dynamics of workplace and use of soft skills.

Keywords: Competency, Dental students, Patients' assessment, Soft skills.

How to cite this article: Mohamed AM, Abdullah D, Dom TNM. Soft Skills of Dental Students' Competence: What is Important for Patients and How do Students Fare? World J Dent 2017;8(3):157-163.

${ }^{1}$ Department of Orthodontics, Faculty of Dentistry, Universiti Kebangsaan Malaysia, Kuala Lumpur, Malaysia

${ }^{2}$ Unit of Endodontics, Department of Operative Dentistry, Faculty of Dentistry, Universiti Kebangsaan Malaysia, Kuala Lumpur Malaysia

${ }^{3}$ Department of Dental Public Health, Faculty of Dentistry Universiti Kebangsaan Malaysia, Kuala Lumpur, Malaysia

Corresponding Author: AM Mohamed, Department of Orthodontics, Faculty of Dentistry, Universiti Kebangsaan Malaysia, Kuala Lumpur, Malaysia, Phone: +60392897588 e-mail: alizaemarny@gmail.com
Source of support: The first stage of the study was funded by Fundamental Research Grant Scheme Ministry of Higher Education (DD-03-FRGS001-2006). The second stage of the study was funded by Strategic Action Research Plan Grant (PTS-2011-1153).

\section{Conflict of interest: None}

\section{INTRODUCTION}

It is a belief of a continuous quality improvement (CQI), which is a process-based approach, that there is always room for improving processes, activities, initiatives, and evaluation efforts to increase the quality of the graduates. One way in achieving this is the curriculum philosophy that should support the alignment between the clinical activities and assessment of student learning in the development of the students' soft skills. A theory-based management system that looks at processes/outcomes in education consists of the culture, client-centered philosophy, instruments to help quantify what we do, system, process and client feedback, and shared success that involve a long-term approach. Defining quality has ever been a big challenge in the field of services, and education has been the most challenging one. There are more tools to improve quality when considering products and evaluating the product line. It is also easier to assess the extent of products' improvement.

All dental programs aspire to produce dental graduates who are competent in their scientific knowledge and clinical skills and are able to demonstrate good attitudes and values so that they can practice good quality, safe, and independent dentistry. ${ }^{1}$ Within the last couple of decades, more dental researchers recognize that technical skills alone are inadequate as patients report less satisfaction with treatment by dentists who exhibit poor interpersonal skills. ${ }^{1,2}$ Such skills need to be developed, and hence, there must be sufficient room in the undergraduate dental curriculum for students to develop them. Gonzalez et $\mathrm{al}^{2}$ found that soft skills in dental training have been described to include various elements, such as communication skills, critical thinking, teamwork, leadership, professionalism, lifelong learning, and entrepreneurship. The authors highlighted the elements of soft skills training that include all elements as aforementioned, with the addition of information management skills and an emphasis on ethics and moral added to the professionalism element. 
Soft skills, as defined by Perreault, ${ }^{3}$ are personal qualities, attributes, or the level of an individual that sets the individual apart from others who may have similar skills and experience. Dental care is about treating oral diseases and improving oral health as this is an integration part of general care. Additionally, it must be concerned about responding to patient needs and wishes - this is to a large extent dependent on the care providers' personal qualities. It is not surprising that investigations on factors affecting patient satisfaction found that when it comes to dentist characteristics, patients tend to rank interpersonal relationship as of utmost importance. ${ }^{4,5}$ This emphasizes the importance of soft skills among dental clinicians. Students who have the ability to acquire and subsequently master such skills can gain further understanding of patients' needs, engage in tasks that will fulfill patients' expectations, and enable them to gain more control in their academic development and growth. To achieve this, the dental education experience must provide the right environment and appropriate assessment methods of the learners' cognitive and behavioral development within the curriculum.

In dental education, the assessment of the students' soft skills provides a challenge to educators in terms of its validity, reliability, and comprehensiveness. Soft skills are typically measured through feedback of the clinical instructor at chairside, self-assessment, or students' reflection, and through examinations, such as designated stations at the objective structured clinical examination. Interestingly, of late there has been a greater effort to include feedbacks from recent graduates and their employees in evaluating the effectiveness of soft skills training in the dental school environment..$^{6-8}$ On this note, the inclusion of patients - who are recipients of dental care-has great potential as a source of authentic feedback of the students' soft skills but has yet to be fully explored.

The development of a new assessment tool to evaluate dental students' communication skills was recently undertaken. ${ }^{7}$ This tool had included patients and other stakeholders (clinical instructors and support staff) in the generation of items that were considered important to assess communication skills. Patients' involvement in developing such evaluation tools is invaluable as it provides their perspective on expectations of care provided by the clinicians, which would otherwise have been missed out by other parties. ${ }^{\text {? }}$

This study is part of a larger effort by the dental school to develop an effective and comprehensive model for CQI in dental education. To further enhance these efforts to assess, improve, and maintain the quality of dental education in the university, evaluations are carried out using both internal and external processes. ${ }^{8-10}$ Patients who receive treatment performed by dental students at the dental school constitute a group of major stakeholders in determining the quality of care as they are the direct recipients of dental care in the clinical setting. Before this study, there had not been any attempt to engage them in efforts to improve the quality of our services. Clinical instructors are recommended to provide feedback for students on ways to improve their soft skills while managing their patients in the clinical setting. However, it was only later that we introduced a formal assessment of the students' soft skills as a component of formative evaluation as well as to improve the effectiveness of instructor feedback.

This study aims (1) to develop an instrument to measure students' soft skills using input given by patients; (2) to measure soft skills of dental students as rated by their patients, and (3) to compare the impact of formal assessment on students' soft skills.

\section{MATERIALS AND METHODS}

The study was conducted in three phases: (1) Development of the Dental Students' Soft Skills Instrument (DSSSI); (2) evaluation of students' soft skills by patients using the DSSSI; and (3) repeat of DSSSI evaluation on a cohort of dental students who received formal assessment of their chairside interpersonal skills on a daily basis.

The study was performed in accordance with the World Medical Association Declaration of Helsinki, and the study protocol was approved by the Ethics Committee. Information sheets were given to the patients to explain the purpose of the study and its nature. We ensured that patients' participation was voluntary, they could withdraw at any time, and that confidentiality was protected. All responses were anonymized and particular care was taken not to reveal potentially identifying details of the students (clinician). It was also explained to patients that their decision to participate (or not) in the study would not affect their relationship with the students. Patients who agreed to participate signed the consent form.

\section{Phase I: Development of the Dental Students' Soft Skills Instrument}

Step 1: A set of items related to patient satisfaction with a dental visit was generated by going through the literature and samples of existing patient satisfaction survey forms. This resulted in 43 items related to dentist behavior and the dental clinic organization.

Step 2: In the nature of the qualitative study, 20 adult patients were interviewed and they were asked to select items they thought were important, and they ranked the top five items they felt to be the most important in relation to dentist behavior and dental clinic organization. This resulted in 32 items - 15 items were related to dentist behavior.

Step 3: The 32 question items were translated from English language to the Malay language. Face validity was per- 
formed followed by pretesting the clarity and sequencing of the questionnaire on 10 dental patients.

Step 4: The internal consistency of the questionnaire was tested on 60 first-time adult patients using Cronbach's alpha.

Step 5: Pilot study for the questionnaire was carried out on 196 patients attending primary dental care clinic at the faculty. Based on this pilot study, we dropped six items and constructed the final instrument as a questionnaire comprising eight items. This was done following the modification of the validated instrument and for the purpose of reducing the number of items.

\section{Phase II: Evaluation of Dental Students' Soft Skills}

The final instrument consisted of eight items related to the dentist behavior section. For each item, we used a 5-point Likert rating scale ranging from 1 (highly dissatisfied) to 5 (highly satisfied). We performed the first evaluation in year 2009 on a group of final year students' adult patients. Students were asked to distribute the DSSSI to three of their patients who were under their care for at least two dental visits.

\section{Phase III: Repeated Evaluation of Dental Students' Soft Skills on Cohort who had Formal Assessment of their Soft Skills}

The faculty introduced the inclusion of formal assessment of soft skills as a component of formative assessment for the final year students in 2010. This formal assessment included elements of professionalism, patient empathy, knowledge, organization of work area, and time management. Therefore, in this phase, the students were aware of their soft skills being evaluated by the clinical instructor, in which the marks were not included in this study. We repeated the same conduct of distributing the DSSSI on the 2011 cohort to the students' patients.

\section{Statistical Methods}

The data were entered and analyzed using the IBM Statistical Package for the Social Sciences software version 20. Data analysis included frequency distributions, reliability analysis, namely, the Cronbach's alpha, Chi-square test, and the Fisher's exact test (level of significance was set at $5 \%$ ).

\section{RESULTS}

\section{Phase I: Dental Students' Soft Skills Instrument Questionnaire Development}

\section{Internal Consistency of the Dental Students' Soft Skills Instrument Items}

Based on the original 15 tested items, we dropped 2 items from the questionnaire to improve the intraitem internal consistency. From the remaining 13 items, we reorganized the scale measuring dentist behavior into seven items, namely communication skills, professionalism, concern, cautiousness, respect for confidentiality, leadership qualities, and punctuality. All items had good internal consistency of $\geq 0.8$, suggesting a high level of reliability (Table 1 ).

\section{The Final Instrument Dental Students' Soft Skills Instrument}

In this study, the final instrument items represented all the seven items except for an additional general question; "overall personality while giving treatment." The final eight items selected by patients to represent the dentists' soft skills are shown in Tables 2 and 3.

\section{Phase II and III: Soft Skill Questionnaire Survey}

\section{The Respondents}

All final year students participated in this study and distributed questionnaires to their patients. The response rates of the patients were $84 \%(n=190)$ and $93 \%(n=153)$ for 2009 and 2011 respectively. However, three questionnaire forms from 2009 were excluded because they were incompletely filled. Therefore, only 187 respondents were included in the assessment for the year 2009. The majority of the respondents were aged between 20 and 30 years, female, Malay, and had obtained at least a diploma (Table 4). There is no major difference between genders, ethnicity, and education level between respondents in 2009 and 2011.

\section{Soft Skills Evaluation}

We grouped the distribution of the scores and mean of each statement by the respondents into two categories: $\leq 3$ (highly dissatisfied, dissatisfied, and somewhat satisfied) and 4 to 5 (satisfied, highly satisfied). A huge proportion (at least 90\%) of the respondents for the 2009 cohort was either satisfied or highly satisfied with all the soft skills

Table 1: Dentist behavior subscale

\begin{tabular}{|c|c|c|c|c|c|c|c|}
\hline \multicolumn{8}{|c|}{ Patients' feedback on dentist behavior } \\
\hline Subscale & Communication & Professionalism & Concern & Cautiousness & Confidential & Leadership & Punctuality \\
\hline Number of items & 2 & 2 & 4 & 2 & 1 & 1 & 1 \\
\hline $\begin{array}{l}\text { Reliability analysis } \\
\text { (Cronbach's alpha) }\end{array}$ & 0.84 & 0.82 & 0.83 & 0.83 & 0.81 & 0.82 & 0.82 \\
\hline
\end{tabular}


Table 2: Respondents' assessment of the students' soft skill by two scored categories

\begin{tabular}{|c|c|c|c|c|c|}
\hline \multirow[b]{2}{*}{ Statement } & \multirow[b]{2}{*}{ Scored } & \multicolumn{2}{|c|}{ Year, $n(\%)$} & \multirow[b]{2}{*}{ Total } & \multirow[b]{2}{*}{$p$-value } \\
\hline & & 2009 & 2011 & & \\
\hline \multirow[t]{3}{*}{ Explanation given about my dental problem } & $\leq 3$ & $20(11)$ & $13(8)$ & $153(100)$ & 0.619 \\
\hline & $4-5$ & $167(89)$ & $140(92)$ & $187(100)$ & \\
\hline & Mean (SD) & $4.24(0.79)$ & $4.29(0.63)$ & & \\
\hline \multirow[t]{3}{*}{ Time spent to treat me } & $\leq 3$ & $24(13)$ & $13(8)$ & $153(100)$ & 0.270 \\
\hline & $4-5$ & $163(87)$ & $140(92)$ & $187(100)$ & \\
\hline & Mean (SD) & $4.23(0.8)$ & $4.31(0.62)$ & & \\
\hline \multirow[t]{3}{*}{ Emotional support given to me (e.g., reduced my anxiety or fear) } & $\leq 3$ & $21(11)$ & $17(11)$ & $153(100)$ & 1.00 \\
\hline & $4-5$ & $166(89)$ & $136(89)$ & $187(100)$ & \\
\hline & Mean (SD) & $4.24(0.79)$ & $4.20(0.62)$ & & \\
\hline \multirow[t]{3}{*}{ Respect given to my privacy during treatment } & $\leq 3$ & $13(7)$ & $8(5)$ & $153(100)$ & 0.667 \\
\hline & $4-5$ & $174(93)$ & $145(95)$ & $187(100)$ & \\
\hline & Mean (SD) & $4.36(0.77)$ & $4.39(0.58)$ & & \\
\hline \multirow[t]{3}{*}{ Treatment given in gentle and comfortable manner } & $\leq 3$ & $16(9)$ & $7(5)$ & $153(100)$ & 0.216 \\
\hline & $4-5$ & $171(91)$ & $146(95)$ & $187(100)$ & \\
\hline & Mean (SD) & $4.41(0.79)$ & $4.42(0.58)$ & & \\
\hline \multirow{3}{*}{$\begin{array}{l}\text { Good example given as a health practitioner (e.g., keep the teeth } \\
\text { clean, no smoking, etc.) }\end{array}$} & $\leq 3$ & $15(8)$ & $8(5)$ & $153(100)$ & 0.422 \\
\hline & $4-5$ & $172(92)$ & $145(95)$ & $187(100)$ & \\
\hline & Mean (SD) & $4.43(0.78)$ & $4.47(0.61)$ & & \\
\hline \multirow[t]{3}{*}{ Punctuality in starting treatment } & $\leq 3$ & $33(18)$ & $15(10)$ & $153(100)$ & 0.056 \\
\hline & $4-5$ & $154(82)$ & $138(90)$ & $187(100)$ & \\
\hline & Mean (SD) & $4.13(0.84)$ & $4.29(0.63)$ & & \\
\hline \multirow[t]{3}{*}{ Overall personality while giving treatment } & $\leq 3$ & $10(5)$ & $6(4)$ & $153(100)$ & 0.719 \\
\hline & $4-5$ & $177(95)$ & $147(96)$ & $187(100)$ & \\
\hline & Mean (SD) & $4.45(0.75)$ & $4.48(0.57)$ & & \\
\hline
\end{tabular}

SD: Standard deviation

Table 3: Soft skills items

\begin{tabular}{lllll}
\hline & & \multicolumn{2}{c}{ Median (IQR) } \\
\cline { 3 - 4 } Items & & 2009 & 2011 & p-value \\
\hline A & Explanation given about my dental problem & $4.00(4.00-5.00)$ & $4.00(4.00-5.00)$ & 0.998 \\
B & Time spent to treat me & $4.00(4.00-5.00)$ & $4.00(4.00-5.00)$ & 0.719 \\
C & Emotional support given to me (e.g., reduced my anxiety or fear) & $4.00(4.00-5.00)$ & $4.00(4.00-5.00)$ & 0.226 \\
D & Respect given to my privacy during treatment & $4.00(4.00-5.00)$ & $4.00(4.00-5.00)$ & 0.657 \\
E & Treatment given in gentle and comfortable manner & $5.00(5.00-5.00)$ & $4.00(4.00-5.00)$ & 0.370 \\
F & Good example given as a health practitioner (e.g., keep the teeth clean , & $5.00(5.00-5.00)$ & $5.00(5.00-5.00)$ & 0.840 \\
& no smoking, etc.) & & & \\
G & Punctuality in starting treatment & $4.00(4.00-5.00)$ & $4.00(4.00-5.00)$ & 0.189 \\
H & Overall personality while giving treatment & $5.00(5.00-5.00)$ & $5.00(5.00-5.00)$ & 0.800 \\
\hline
\end{tabular}

IQR: Interquartile range

Table 4: Sociodemographic characteristics

\begin{tabular}{lll}
\hline \multirow{2}{*}{$\begin{array}{ll}\text { Variables } \\
\text { Age (years) }\end{array}$ 20 } & \multicolumn{2}{c}{ Number of patients } \\
\cline { 2 - 3 } $20-30$ & $12(6.4)$ & $12(67.8)$ \\
$31-40$ & $89(46.0)$ & $52(34.0)$ \\
$41-50$ & $20(10.7)$ & $24(15.7)$ \\
$\geq 51$ & $37(19.8)$ & $29(19.0)$ \\
Gender & $30(16.0)$ & $27(17.6)$ \\
Male & & \\
Female & $63(33.7)$ & $67(43.8)$ \\
Education & $124(66.3)$ & $84(54.9)$ \\
Primary & & \\
Secondary & $8(4.3)$ & $6(3.9)$ \\
Diploma and above & $82(43.3)$ & $57(37.3)$ \\
Others & $80(47.1)$ & $82(53.6)$ \\
No response & $0(0)$ & $4(2.6)$ \\
\hline Total & $10(5.3)$ & $4(2.6)$ \\
\hline
\end{tabular}

items except for punctuality ( $82 \%)$. We observed the same high level of satisfaction pattern for the 2011 patient cohort. In addition, over $95 \%$ of patients were satisfied/ highly satisfied with overall personality of the dental students in both cohorts.

\section{DISCUSSION}

This study is an attempt to illustrate the importance of taking into consideration patients' needs and expectations as recipients of dental care when developing a tool to measure dental students' soft skills at chairside. Today's patients are more informed, more concerned, responsible, and able to make decisions for quality of health care that they received..$^{10}$ Their satisfaction is deemed to be one of the most important factors that determines the success of health care being provided. As such, patients' 
feedback of the individual dentist's soft skills should not be disregarded when evaluating the dentist's clinical performance as these skills form the core competency of clinical practice. ${ }^{4,9-12}$

It is interesting to note that they include both verbal (Items 1 and 3; Table 3) and nonverbal communication skills (Items 2, 4, 5, 6, and 7; Table 3). Nonverbal items outnumbered verbal ones. The value of patients' first impression in this study, such as related to appearance/attire that exemplifies professional integrity, displaying effective time management, and use of appropriate language affecting their confidence, comfort, and anxiety levels is consistent with what is reported in the literature. ${ }^{11}$ While there is no one way to define "professionalism," the notion of a dentist being professional includes all aspects of working attributes, including being a good role model with regard to oral health behavior. ${ }^{13,14}$ Dental students themselves have been shown to value the importance of dentists displaying neat clothing, healthy smiles, and punctuality - attributes which are not broadly discussed as dentists' core competencies. Punctuality implies the ability to quickly recognize and solve management and organizational problems that become factors leading to success during clinical encounters. Long waiting times have been reported to be one of the major reasons for dissatisfaction with dental visits; ${ }^{15,16}$ however, they may be acceptable if dental treatment appears to be reasonably well tolerated. ${ }^{17}$ In addition, the period spent waiting for dental treatment is cited commonly by patients as being anxiety-provoking, as it increases the time for the patients to think about what will happen. A combination of patient anxiety and lack of practitioner punctuality in delivering treatments may negatively impact patients' perceptions of the quality of service delivery.

Item 1 in Tables 2 and 3 highlights communications skills as a major competence that represent the broad categories of professional activity in dentistry. ${ }^{18}$ At present, various methods have been employed and showed to aid the teaching of communication skills among dental students. ${ }^{19,20}$ Good communication is considered as a major driver of a dentist's soft skills because it has a variety of complex elements, such as informed choice, patient education, motivation, adherence, emotional exchange, and relationship building. ${ }^{21,22}$ It positively affects daily interaction between dentist and patient, such as in the improvement of patient's health, the establishment of doctor-patient relationship, and increase in patients' satisfaction. ${ }^{5,23}$ In contrast, a lack of communication may arise from the use of too many technical terms that the patient does not understand, hence, making it difficult for patient to participate in their own health care. ${ }^{24}$

This study shows that the patients value the time spent by the students with them (Item 2; Tables 2 and 3).
Adequate time must be accorded by dentists to enable information sharing and to provide clear explanations with regard to patient condition and treatment. In fact, information-giving has been highlighted as an important interpersonal factor that affects patient satisfaction with dental care. ${ }^{12}$ It is important for dental students to listen to what patients tell them, pay attention to their concerns, and treat them as individuals. ${ }^{25}$ However, some barriers to effective communication do exist, such as structural obstacles of time constraints, ${ }^{26}$ lack of experience/ practice, and skills in cultural competency among clinicians; uneasiness to establish rapport with patients from different backgrounds. ${ }^{27}$

Majority of patients in this study expected the students to assist them in alleviating fear and anxiety (Item 3; Tables 2 and 3). Epidemiological studies recognize dental fear as one of the most common types of fear, ${ }^{28,29}$ while anxiety is seen to be commonly related to individual vulnerability and traumatic dental care experiences. ${ }^{30} \mathrm{Nega-}$ tive dentist behavior plays a significant role in arousing patient anxiety although as a person, dentists have been found to be one of the least fear-evoking aspects. ${ }^{12,31,32}$ Patients identify that the major influence of anxiety reduction during dental treatment is the dentist's explicit dedication to prevent pain, followed by dentist other attributes, such as being friendly, working quickly, being calm, and giving moral support. ${ }^{33}$ Moreover, demonstrating empathy and comforting patients through effective communication strategies have a positive influence on reducing their anxiety levels. ${ }^{34}$

Patients appear to view that they should be given privacy and treatment in a good manner (Item 4; Tables 2 and 3). Maintaining confidentiality is a sign of respect for the patients' right for personal privacy. Revealing personal and sensitive information is not easy to do even if it may be crucial for dental procedures. Respect for the patient's sense of individuality and privacy is necessary to establish rapport and trust..$^{21,22,35}$ When patients feel encouraged to communicate honestly and forthrightly, dentist will be able to obtain and make accurate history and diagnosis respectively. Increased trust in the dentist will also lead to more patient compliance toward dental treatment, visits, and home care. Studies have reported that dental students' humanistic qualities in their early years are associated with their clinical performance during the later years of training. ${ }^{36,37}$ Dentists are expected to offer personalized dental care in a genuinely caring and supportive atmosphere (Item 5; Tables 2 and 3).

In this study, both groups of students received a general training in their soft skills or interpersonal skills during preclinical years through didactic approach. These soft skills were then developed during their clinical 
years, starting from role play sessions to actual clinical encounters. We wanted to know if there would be further improvements in their soft skills if a formal assessment was added after their clinical sessions. We observe that there were high levels of patient satisfaction with soft skills of both cohorts as evaluated by their own patients. Findings were consistent between both cohorts although formal assessment was only conducted for the 2011 cohort. This suggests that the formal assessment did not have any impacts on the development of the students' soft skills. This is in spite of the efforts expended by the faculty, which can be described as very time-consuming and resource-demanding. ${ }^{38,39}$ Related, it is difficult to achieve the consistency of evaluation among clinical instructors and clarity of the assessment purpose which was aimed to reflect students' professional behavior. ${ }^{39,40}$ For any assessment system to be accurately mapped against a school's educational aims and objectives, the system should be embedded throughout its teaching-learning curriculum. As complexity of clinical cases increases, students must be made aware of the increasing demands on them to perform clinically, including in the aspect of interpersonal skills, and especially during difficult clinical situations. As it seems that the present formal assessment was not able to further improve patients' satisfaction with students' soft skills, it is perhaps necessary that the nature of the formal assessment be studied specifically with regard to how an instructor conveys their feedback to the learner on ways to improve their performance. It is sensible that in this regard a formative assessment of soft skills should be considered as more critical than a summative one.

This study is limited by its cross-sectional nature, and hence, the scope was assessment of students during a point in time for each cohort. This method of assessment was chosen in the light of difficulty in following up the same cohort of students over time. Ideally, all patients should be included to provide the feedback on the students' soft skills. The patients' experience will allow CQI becomes a regular part of both the educational as well as the clinical activities. Besides that, it is also recognized that soft skills will evolve and improve over time as students acquire more clinical experience over the entire duration of their clinical training; hence, comparing two cohorts on their respective exit points is also acceptable. Another possible weakness is that the patients were determined by the students themselves; there is a possibility that the selection could be biased toward patients who were easier to manage clinically. In addition, patients may also be motivated to provide positive feedback and also they tend to be kind to the students.

\section{CONCLUSION}

Patients were equally satisfied with the soft skills among two groups during clinical encounters regardless if they had been exposed to a formal assessment of the skills. While it is beneficial to include patient feedback as part of the dental school CQI initiative, the formal assessment of soft skills at chairside did not appear to have any impacts on the measured outcomes.

Apart from constructive feedback given by clinical instructors, patient feedback as the recipient of care should be taken into serious consideration as part of an ongoing CQI initiative. The strength of the DSSSI was that it was brief and easy to administer that involving not only patient's perceptions but also their expectations and beliefs about what constitutes a dental student's standard of duty.

\section{CLINICAL SIGNIFICANCE}

In general, acquiring relevant chairside interpersonal skills is necessary so that dental students can organize, plan, and manage their vast learning experiences and deal with different situations during clinical encounters. The ability to respond to the patient's needs and meeting their expectations satisfactorily will strengthen students from within, and this makes a good predictor of academic success within the undergraduate dental curriculum and beyond.

\section{ACKNOWLEDGMENT}

The authors are grateful to the undergraduate dental students for their cooperation and participation in this study.

\section{REFERENCES}

1. Kulich KR, Rydén O, Bengtsson H. A descriptive study of how dentists view their profession and the doctor-patient relationship. Acta Odontol Scand 1998 Aug;56(4):206-209.

2. Gonzalez MA, Abu Kasim NH, Naimie Z. Soft skills and dental education. Eur J Dent Educ 2013 May;17(2):73-82.

3. Perreault $\mathrm{H}$. Business educators can take a leadership role in character education. Bus Educ Forum 2004;59:23-24.

4. Newsome PR, Wright GH. Qualitative techniques to investigate how patients evaluate dentists: a pilot study. Community Dent Oral Epidemiol 2000 Aug;28(4):257-266.

5. Sbaraini A, Carter SM, Evans RW, Blinkhorn A. Experiences of dental care: what do patients value? BMC Health Serv Res 2012 Jun;12:177.

6. Razak IA, Latifah RR, Jaafar N, Abu Hassan MI, Ab Murat N. Assessing the competency of University of Malaya dental graduates: employers' and graduates' perceptions. J Dent Educ 2008 Mar;72(3):364-369.

7. Wener ME, Schönwetter DJ, Mazurat N. Developing new dental communication skills assessment tools by including patients and other stakeholders. J Dent Educ 2011 Dec;75(12):1527-1541. 
8. Boyd LD. Development of reflective judgement in the predoctoral dental clinical curriculum. Eur J Dent Educ 2008 Aug;12(3):149-158.

9. Hendricson WD, Andrieu SC, Chadwick DG, Chmar JE, Cole JR, George MC, Glickman GN, Glover JF, Goldberg JS, Haden NK, et al. Educational strategies associated with development of problem-solving, critical thinking, and selfdirected learning. J Dent Educ 2006 Sep;70(9):925-936.

10. Rohlin M, Schaub RM, Holbrook P, Leibur E, Lévy G, Roubalikova L, Nilner M, Roger-Leroi V, Danner G, Iseri H, et al. 2.2 Continuous quality improvement. Eur J Dent Educ 2002;6 (Suppl 3):67-77.

11. Brosky ME, Keefer OA, Hodges JS, Pesun IJ, Cook G. Patient perceptions of professionalism in dentistry. J Dent Educ 2003 Aug;67(8):909-915.

12. Newsome PR, Wright GH. A review of patient satisfaction: 2 . Dental patient satisfaction: an appraisal of recent literature. Br Dent J 1999 Feb;186(4) Spec No:166-170.

13. Trathen A, Gallagher JE. Dental professionalism: definitions and debate. Br Dent J 2009 Mar;206(5):249-253.

14. Masella RS. Renewing professionalism in dental education: overcoming the market environment. J Dent Educ 2007 Feb;71(2):205-216.

15. Esa R, Rajah P, Abdul Razak I. Satisfaction with the oral health services. A qualitative study among Non-Commissioned Officers in the Malaysian Armed Forces. Community Dent Health 2006 Mar;23(1):15-20.

16. Chu CH, Lo EC. Patients' satisfaction with dental services provided by a university in Hong Kong. Int Dent J 1999 Feb;49(1):53-59.

17. Tuominen R, Eriksson AL. Patient experiences during waiting time for dental treatment. Acta Odontol Scand 2012 Jan;70(1):21-26.

18. Carey JA, Madill A, Manogue M. Communications skills in dental education: a systematic research review. Eur J Dent Educ 2010 May;14(2):69-78.

19. Hannah A, Millichamp CJ, Ayers KM. A communication skills course for undergraduate dental students. J Dent Educ 2004 Sep;68(9):970-977.

20. Omar H, Khan SA, Toh CG. Structured student-generated videos for first-year students at a dental school in Malaysia. J Dent Educ 2013 May;77(5):640-647.

21. Lahti S, Tuutti H, Hausen H, Käärlänen R. Patients' expectations of an ideal dentist and their views concerning the dentist they visited: do the views conform to the expectations and what determines how well they conform? Community Dent Oral Epidemiol 1996 Aug;24(4):240-244.

22. Yamalik N. Dentist-patient relationship and quality care 3. Communication. Int Dent J 2005 Aug;55(4):254-256.

23. Schouten BC, Eijkman MA, Hoogstraten J. Dentists' and patients' communicative behaviour and their satisfaction with the dental encounter. Community Dent Health 2003 Mar;20(1):11-15.

24. Edwards A, Elwyn G. Involving patients in decision making and communicating risk: a longitudinal evaluation of doctors' attitudes and confidence during a randomized trial. J Eval Clin Pract 2004 Aug;10(3):431-437.

25. Logan HL. The patient and the shifting health-care paradigm. J Am Coll Dent 1997 Spring;64(1):16-18.

26. Edwards A, Elwyn G, Wood F, Atwell C, Prior L, Houston H. Shared decision making and risk communication in practice: a qualitative study of GPs' experiences. Br J Gen Pract 2005 Jan;55(510):6-13.

27. Broder HL, Janal M. Promoting interpersonal skills and cultural sensitivity among dental students. J Dent Educ 2006 Apr;70(4):409-416.

28. Agras S, Sylvester D, Oliveau D. The epidemiology of common fears and phobia. Compr Psychiatry 1969 Mar;10(2): 151-156.

29. Oosterink FM, de Jongh A, Hoogstraten J. Prevalence of dental fear and phobia relative to other fear and phobia subtypes. Eur J Oral Sci 2009 Apr;117(2):135-143.

30. de Jongh A, Fransen J, Oosterink-Wubbe F, Aartman I. Psychological trauma exposure and trauma symptoms among individuals with high and low levels of dental anxiety. Eur J Oral Sci 2006 Aug;114(4):286-292.

31. Oosterink FM, de Jongh A, Aartman IH. What are people afraid of during dental treatment? Anxiety-provoking capacity of 67 stimuli characteristic of the dental setting. Eur J Oral Sci 2008 Feb;116(1):44-51.

32. Abrahamsson $\mathrm{KH}$, Berggren U, Hallberg L, Carlsson SG. Dental phobic patients' view of dental anxiety and experiences in dental care: a qualitative study. Scand J Caring Sci 2002 Jun;16(2):188-196.

33. Corah NL, O'Shea RM, Bissell GD, Thines TJ, Mendola P. The dentist-patient relationship: perceived dentist behaviors that reduce patient anxiety and increase satisfaction. J Am Dent Assoc 1988 Jan;116(1):73-76.

34. Abrahamsson KH, Berggren U, Hakeberg M, Carlsson SG. The importance of dental beliefs for the outcome of dentalfear treatment. Eur J Oral Sci 2003 Apr;111(2):99-105.

35. Yamalik N. Dentist-patient relationship and quality care 2 . Trust. Int Dent J 2005 Jun;55(3):168-170.

36. Kalenderian E, Maramaldi P, Kinnunen TH, Spinell D, Nelson LP. Assessing early performance in the patient-doctor relationship in dental education. J Dent Educ 2012 Feb;76(2): 159-167.

37. Nelson LP, Maramaldi P, Kinnunen TH, Kalenderian E. Early performance in a humanistic medicine course as a predictor of dental students' later clinical performance. J Dent Educ 2013 Aug;77(8):1006-1012.

38. Arnold L. Assessing professional behavior: yesterday, today, and tomorrow. Acad Med 2002 Jun;77(6):502-515.

39. Wilkinson TJ, Wade WB, Knock LD. A blueprint to assess professionalism: results of a systematic review. Acad Med 2009 May;84(5):551-558.

40. Clauser BE, Margolis MJ, Holtman MC, Katsufrakis PJ, Hawkins RE. Validity considerations in the assessment of professionalism. Adv Health Sci Educ Theory Pract 2012 May;17(2):165-181. 